\title{
Impact of Histopathological Risk Factors on the Treatment of Stage IB-IIB Uterine Cervical Cancer
}

\author{
Muneaki Shimada, ${ }^{1}$ Hideki Tokunaga, ${ }^{1}$ Junzo Kigawa $^{2}$ and Nobuo Yaegashi ${ }^{1}$ \\ ${ }^{1}$ Department of Obstetrics and Gynecology, Tohoku University Graduate School of Medicine, Sendai, Miyagi, \\ Japan \\ ${ }^{2}$ Department of Obstetrics and Gynecology, Matsue City Hospital, Matsue, Shimane, Japan
}

\begin{abstract}
In the past decade, the incidence of adenocarcinoma of the uterine cervix gradually increased. Recent literature revealed that the molecular pathogenesis differs by histological subtype, and the histological subtype should be considered in deciding treatments for patients with uterine cervical cancer. However, no treatment based on histological type or genomic signature has been recommended in various treatment guidelines. The Japanese treatment guidelines recommend either radical hysterectomy or definitive radiotherapy as primary treatment for patients with stage IB-IIB squamous cell carcinoma and a radical hysterectomy-based approach for those with non-squamous cell carcinoma because of its lower radiosensitivity. The impact of histological type on survival outcome of uterine cervical cancer is controversial. Our retrospective studies suggested that the difference in survival outcome by histological subtype might be remarkable with disease progression. Recent literature suggested that usual-type endocervical adenocarcinoma, which is the most common histological type of cervical adenocarcinoma, showed a similar survival outcome to squamous cell carcinoma. In contrast, gastric-type mucinous carcinoma of the uterine cervix, which has aggressive clinical behavior and is not associated with high-risk human papillomavirus infection, showed resistance to chemotherapy and radiotherapy. Importantly, gastrictype mucinous carcinoma is rather common in Japan, compared with Western countries. It is therefore conceivable that the survival outcome of non-squamous cell carcinoma may be affected by regional difference in the frequency of gastric-type mucinous carcinoma. A molecular target to refractory uterine cervical cancer, such as gastric-type mucinous carcinoma of uterine cervix, still remains to be identified.
\end{abstract}

Keywords: chemotherapy; concurrent chemoradiotherapy; radical hysterectomy; radiotherapy; uterine cervical cancer Tohoku J. Exp. Med., 2020 December, 252 (4), 339-351.

\section{Introduction}

Uterine cervical cancer (UCC) was the fourth common female malignancy, which accounted for approximately 570,000 new cases and 311,000 deaths worldwide in 2018 (Arbyn et al. 2020). In Japan, UCC is also one of the most common female malignancies with 7,304 newly diagnosed women in 2018, and 1,591 women (21.8\%) were diagnosed with non-squamous cell carcinoma (nSCC) (Yaegashi 2020). In the past decade, the incidence of adenocarcinoma of the uterine cervix increased from approximately $5 \%$ to $20 \%$ of cervical cancers (Smith et al. 2000).

World Health Organization (WHO) Classification of
Tumor of Female Reproductive Organs 2014 (Wibur et al. 2014) classified 11 histological subtypes by descriptive morphologic characteristics and primarily cytoplasmic features as following: i) Endocervical adenocarcinoma, usual type (UEA); ii) Mucinous carcinoma, not otherwise specified (NOS); iii) Mucinous carcinoma, gastric type (GAS); iv) Mucinous carcinoma, intestinal type; v) Mucinous carcinoma, signet ring cell type; vi) Villoglandular carcinoma; vii) Mesonephric carcinoma; viii) Serous carcinoma; ix) Clear cell carcinoma; x) Endometrioid carcinoma; and xi) Adenocarcinoma, NOS. In addition, the international endocervical adenocarcinoma criteria and classification (IECC) proposed to categorize endocervical adenocarci-

Received July 15, 2020; revised and accepted November 17, $2020 . \quad$ Published online December 11, 2020; doi: 10.1620/tjem.252.339. Correspondence: Muneaki Shimada, Ph.D., M.D., Department of Obstetrics and Gynecology, Tohoku University School of Medicine, 1-1 Seiryo-machi, Aoba-ku, Sendai, Miyagi 980-8574, Japan.

e-mail: muneaki.shimada.b7@ tohoku.ac.jp

(C)2020 Tohoku University Medical Press. This is an open-access article distributed under the terms of the Creative Commons Attribution-NonCommercial-NoDerivatives 4.0 International License (CC-BY-NC-ND 4.0). Anyone may download, reuse, copy, reprint, or distribute the article without modifications or adaptations for non-profit purposes if they cite the original authors and source properly.

https://creativecommons.org/licenses/by-nc-nd/4.0/ 
noma by Human papilloma virus (HPV) infectious status as following: HPV-associated (HPVA) and non-HPV-associated (NHPVA). UEA is the most common subtype (more than $75 \%$ of endocervical adenocarcinoma) and is categorized as HPVA by IECC. GAS has been newly categorized in WHO Classification of Tumor of Female Reproductive Organs 2014 (Wibur et al. 2014), and was reported to be the second most common subtype of endocervical adenocarcinoma (Stolnicu et al. 2018). Minimal deviation adenocarcinoma is categorized as extremely well differentiated subtype of GAS. GAS has been also associated with PeutzJeaghers syndrome (Kuragaki et al. 2003).

Although several authors reported that the 5-year overall survival (OS) rate in $\mathrm{nSCC}$ is lower by $10-20 \%$ compared to that in squamous cell carcinoma (SCC) (Irie et al. 2000; Quinn et al. 2006; Galic et al. 2012), the impact of histological type on survival outcome of UCC is controversial (Katanyoo et al. 2012; Kasamatsu et al. 2009; Seamon et al. 2018) (Table 1). The largest retrospective studies using the Surveillance, Epidemiology, and End Results database, which is a premier source for cancer statistics in the United States, suggested that adenocarcinoma histology negatively affected survival for both early- and advancedstage disease compared with SCC (Galic et al. 2012). In contrast, Kasamatsu et al. (2009) reviewed the medical records of 578 patients (endocervical/endometrioid adenocarcinoma, 123; SCC, 455) with stage I to IIB cervical cancer who underwent radical hysterectomy $(\mathrm{RH})$; there was no significant difference in survival outcome between the patient groups separated by histological type (Kasamatsu et al. 2009). Irie et al. (2000) reported that the survival in patients with stage IB UCC did not differ between SCC and nSCC, but in patients with stage II UCC, patients with nSCC showed significantly worse outcome than those with SCC. Shimada et al. (2013b) also demonstrated that histological subtype did not affect the 5-year OS in patients without pelvic lymph node involvement (adenocarcinoma, $91.2 \%$ vs. SCC, $93.9 \%, p=0.4464)$, but in patients with pelvic lymph node involvement, patients with adenocarcinoma had significantly worse outcome than those with SCC (adenocarcinoma, $46.4 \%$ vs. SCC, $72.3 \%, \mathrm{p}=0.0005$ ) in the retrospective studies that included 820 patents with UCC (SCC, 540; adenocarcinoma, 280). Patients who did not receive adjuvant treatment after $\mathrm{RH}$ also showed similar 5 -year OS between SCC and adenocarcinoma (adenocarcinoma, $93.1 \%$ vs. SCC, $94.0 \% ; p=0.9497)$. In contrast, in patients with adjuvant treatment, patients with adenocarcinoma showed significantly worse 5-year OS compared to those with SCC (adenocarcinoma, $73.7 \%$ vs. SCC, $83.1 \%$, $\mathrm{p}=0.0368$ ), suggesting that the difference in survival outcome by histological subtype may be remarkable with disease progression.

Recent literature suggested that adenocarcinoma is clearly different from SCC based on its molecular pathogenesis (Wright et al. 2013; Ojesina et al. 2014) and that the histological subtype should be considered in deciding treatments for patients with UCC. However, no treatment based on histological type or genomic signature has been established for patients with UCC. Consequently, National Comprehensive Cancer Network (NCCN) guidelines recommended that patients with adenocarcinoma should be treated in a similar manner as those with SCC ( NCCN

Table 1. Treatment for stage IB-IIB patients with UCC by clinical stage in Japan.

\begin{tabular}{llccc}
\hline \multirow{2}{*}{ Authors (year) } & \multicolumn{2}{c}{ Numbers of patients } & \multicolumn{2}{c}{5 -year OS } \\
\cline { 2 - 4 } & \multicolumn{1}{c}{ Stage } & SCC/nSCC & SCC/nSCC & p value \\
\hline Irie et al. (2000) & stage IB & $99 / 29$ & $94.4 \% / 95.8 \%$ & NS \\
& stage II & $99 / 28$ & $89.5 \% / 60.7 \%$ & 0.0007 \\
Kantanyoo et al. (2012) & stage IIB & $170 / 85$ & $70.8 \% / 71.9 \%$ & 0.568 \\
& stage IIIB/IVA & $112 / 56$ & $47.4 \% / 41.1 \%$ & 0.139 \\
Kasamatsu et al. (2009) & stage IB & $275 / 96$ & $89 \% / 89 \%$ & 0.640 \\
& stage IIA & $51 / 5$ & $89 \% / 92 \%$ & 0.317 \\
Shimada et al. (2013b) & stage IIB & $129 / 22$ & $62 \% / 38 \%$ & 0.074 \\
& stage IB-II ${ }^{* 1}$ & $377 / 229$ & $93.9 \% / 91.2 \%$ & 0.4464 \\
& stage IB-II ${ }^{* 2}$ & $163 / 51$ & $72.3 \% / 46.4 \%$ & 0.0005 \\
Galic et al. (2012) & stage IB-II ${ }^{* 3}$ & $213 / 141$ & $94.0 \% / 93.1 \%$ & 0.9497 \\
& stage IB-II ${ }^{* 4}$ & $327 / 139$ & $83.1 \% / 73.7 \%$ & 0.0368 \\
& stage I-II & $10,381 / 2,998$ & HR: 1.16 & $95 \%$ CI: $1.05-1.27$ \\
\hline
\end{tabular}

SCC, squamous cell carcinoma; nSCC, non-Squamous cell carcinoma; NS, not significant; HR, hazard ratio; 95\% CI, 95\% confidence Interval.

${ }^{*}$ Patients without lymphnode metastasis.

${ }^{*}$ Patients with lymphnode metastasis.

${ }^{*}$ Patients without adjuvant treatment after surgery.

${ }^{*}$ Patients with adjuvant treatment after surgery. 


\section{Stage IB-IIB}

Patients with squamous cell carcinoma

\begin{tabular}{|l|c|}
\hline Stage IB1, IIA1 & $\mathrm{RH}+$ /- adjuvant treatment or RT/ CCRT \\
\hline Stage IB2, IIA2 & $\mathrm{RH}+/$ - adjuvant treatment or CCRT \\
\hline Stage IIB & $\mathrm{RH}+/$ - adjuvant treatment or CCRT \\
\hline
\end{tabular}

\section{Patients with non-squamous cell carcinoma}

\begin{tabular}{|l|l}
\hline Stage IB-IIB & $\mathrm{RH}+/$ - adjuvant treatment $>$ CCRT
\end{tabular}

2. Stage III, IVA

\section{Stage IVB}

\section{CCRT}

\section{Chemotherapy, palliative RT, or Best supportive care}

Fig. 1. Recommended treatment for patients with uterine cervical cancer by JSGO guidelines 2017.

The Japan Society of Gynecologic Oncology (JSGO) guidelines recommended either RH-based approach or definitive radiotherapy, including concurrent chemoradiotherapy (CCRT), as primary treatment for patients with not only stage IB1, and IIA1 (FIGO 2008) but also stage IB2, IIA2, and IIB (FIGO 2008), especially for non-squamous cell carcinoma. The JSGO guidelines recommended CCRT for patients with stage III-IVA disease, and chemotherapy, palliative radiotherapy, and/or best supportive care for those with stage IVB disease.

Table 2. Treatment for stage IB-IIB patients with UCC by clinical stage in Japan.

\begin{tabular}{lcccr}
\hline Stage & Surgical treatment $^{* 1}$ & Radiotherapy $^{* 2}$ & Others $^{* 3}$ & Total $^{*}$ \\
\hline IB1 & $1,952(89.6 \%)$ & $222(10.2 \%)$ & $5(0.2 \%)$ & 2,179 \\
IB2 & $504(78.8 \%)$ & $130(20.3 \%)$ & $6(0.9 \%)$ & 640 \\
IIA1 & $156(65.0 \%)$ & $84(35.0 \%)$ & 0 & 240 \\
IIA2 & $126(59.2 \%)$ & $86(40.4 \%)$ & $1(0.5 \%)$ & 213 \\
IIB & $452(34.7 \%)$ & $838(64.4 \%)$ & $12(0.9 \%)$ & 1,302 \\
\hline
\end{tabular}

${ }^{*}$ Radical hysterectomy $+/$ - adjuvant treatment including radiotherapy, concurrent chemoradiotherapy, or chemotherapy.

${ }^{*}$ Radiotherapy or Concurrent chemoradiotherapy.

${ }^{*}$ Others included chemotherapy $+/-$ molecular targeting therapy.

2020).

Of 7,304 newly diagnosed women in 2018, 4,607 women (63.1\%) were diagnosed with stage IB/II in Japan (Yaegashi 2020). The NCCN guideline suggested that radical hysterectomy $(\mathrm{RH})$ is performed only in patients with stage IB1, IB2, and IIA1 (International Federation of Gynecology and Obstetrics [FIGO] 2018) UCC (NCCN 2020). In contrast, the Japan Society of Gynecologic Oncology (JSGO) guidelines recommended either RH-based approach or definitive radiotherapy, including concurrent chemoradiotherapy (CCRT), as primary treatment for patients with not only stage IB1, and IIA1 (FIGO 2008) but also stage IB2, IIA2, and IIB (FIGO 2008) (Ebina et al. 2019) (Fig. 1).

Table 2 shows the treatment for patients with stage IB-II UCC in Japan (Yaegashi 2020). A survey of the Japanese Gynecologic Oncology Group (JGOG) reported that CCRT was performed at $53(31.9 \%)$ of 166 institutions for women with stage IIB SCC but only 28 (17.0\%) of 166 institutions for patients with stage IIB nSCC disease (Mikami et al. 2014), suggesting that histological subtype affected the selection of the management modality for patients with UCC in Japan.

This review presents the impact of histological subtype on the treatment and survival outcome of patients with stage IB-IIB UCC.

\section{RH as Primary Treatment for Patients with Stage IB-IIB UCC}

The most important issue of primary treatment for patients with stage IB-IIB UCC was selecting the local control strategy in the pelvic cavity. The difference in surgical methods between Japan and Western countries affects the recommended primary treatment for stage IB-IIB UCC in 
each country. Based on "the Okabayashi's RH method," Japanese gynecologic oncologists established RH with higher curability. The Okabayashi's RH method makes it possible to remove the parametrial tissue widely with separation of the anterior/posterior leaf of the vesico-uterine ligament (Ebina et al. 2019). The JSGO guidelines therefore recommended the RH-based approach as primary localcontrol strategy for patients with IB-IIB UCC.

Importantly, the JGOG retrospective study, which examined clinical data of 5,964 patients with stage IB-IIB UCC who underwent RH, suggested that the hospital volume for RH might deeply affect the survival outcome of patients with stage IB1-IIB UCC, and surgery at high-volume centers was associated with decreased local recurrence risk and improved survival (Matsuo et al. 2019b). Mikami et al. (2018) also suggested that patients with UCC treated in JSGO accredited institutions showed significantly better survival outcome than those in JSGO non-accredited institutions in Japan. Since the curability of RH profoundly affects the outcome in patients with stage IB-IIB UCC, gynecologic oncologists have to strictly examine the patient before treatment and determine which is the better treatment, the RH-based approach or radiotherapy, for patients with stage IB-IIB UCC.

\section{Neoadjuvant Chemotherapy (NAC) Followed by RH}

The aim of the strategy of NAC followed by RH is the goal of downstaging of the tumor to improve the surgical curability and safety of RH and inhibition of micrometastasis and distant metastasis (Ebina et al. 2019). Some authors evaluated the efficacy and safety of NAC followed by RH in patients with stage IB-IIB UCC in prospective studies (Table 3) (Angioli et al. 2012; Yamaguchi et al. 2012; Shimada et al. 2016; Tanioka et al. 2017). However, if patients did not respond to NAC and were not eligible for RH, NAC induced negative impacts of definitive radiotherapy, including CCRT, and decreased the survival of these patients. It remains uncertain whether NAC followed by $\mathrm{RH}$ is beneficial for patients with stage IB3, IIA2, and IIB UCC. As a result, JGOG survey showed that 44 institutions $(45.5 \%)$ in Japan positively performed NAC followed by RH (Mikami et al. 2014).

A Gynecologic Oncology Group (GOG) randomized phase III study (GOG141) revealed that there was no evidence that NAC followed by RH offered any additional benefit to patients with stage IB3 UCC (Eddy et al. 2007). An international collaborative meta-analysis of NAC reported that NAC reduced the need of adjuvant radiother-

Table 3. Perioperative chemotherapy for patients with cervical cancer.

\begin{tabular}{|c|c|c|c|c|c|}
\hline Author (year) & Stage & Histology & Numbers & Regimen & Response rate \\
\hline \multicolumn{6}{|l|}{ Neoadjuvant chemotherapy } \\
\hline Yamaguchi et al. (2012) & IB2-IIB & $\mathrm{SCC}$ & 68 & CPT-11/NDP ${ }^{* 1}$ & $75.8 \%$ \\
\hline Angicli et al. (2012) & IB2-IIB & $\mathrm{SCC} / \mathrm{nSCC}$ & 115 & $\mathrm{PTX} / \mathrm{CDDP}^{*_{2}}$ & $87 \%$ \\
\hline Shimada et al. (2016) & IB2-IIB & $\mathrm{nSCC}$ & 61 & $\mathrm{DTX} \mathrm{CBDCA}^{* 3}$ & $69 \%$ \\
\hline Tanioka et al. (2017) & IB2-IIB & $\mathrm{SCC} / \mathrm{nSCC}$ & 51 & $\mathrm{PTX} / \mathrm{CDDP}^{* 4}$ & $94 \%$ \\
\hline Mori et al. (2019) & IB2-IIB & $\mathrm{SCC}$ & 32 & CPT-11/NDP ${ }^{* 1}$ & $81.2 \%$ \\
\hline Author (year) & Histology & Numbers & Risk & Regimen & 5-year survival rate \\
\hline \multicolumn{6}{|c|}{ Adjuvant chemotherapy after radical hysterectomy } \\
\hline Takeshima et al. (2006) & $\mathrm{SCC} / \mathrm{nSCC}$ & 65 & $\mathrm{IR} / \mathrm{HR}$ & $\mathrm{BLM} / \mathrm{VCR} / \mathrm{MMC} / \mathrm{CDDP}^{* 5}$ & $\begin{array}{l}\text { IR: } 93.3 \%{ }^{\star 1} \\
\text { HR: } 85.7 \%{ }^{\star 1}\end{array}$ \\
\hline Hosaka et al. (2012) & $\mathrm{SCC} / \mathrm{nSCC}$ & 32 & $\mathrm{IR} / \mathrm{HR}$ & PTX/CDDP ${ }^{* 6}$ & $93.8 \%$ \\
\hline Sato et al. (2016) & $\mathrm{nSCC}$ & 37 & HR & PTX or DTX/CBDCA ${ }^{* 7}$ & $64.7 \%$ \\
\hline Matoda et al. (2018) & SCC & 62 & HR & CPT-11/NDP ${ }^{* 1}$ & $86.5 \%$ \\
\hline Takekuma et al. (2018) & $\mathrm{SCC}$ & 62 & HR & $\mathrm{PTX} / \mathrm{NDP}^{* 8}$ & $93.5 \%$ (2-yr OS) \\
\hline
\end{tabular}

SCC, Squamous cell carcinoma; nSCC, non-squamous cell carcinoma; IR, intermediate risk; HR, high risk; OS, overall survival; CPT-11, irinotecan; NDP, nedaplatin; PTX, paclitaxel; CDDP, cisplatin; DTX, docetaxel; CBDCA, carboplatin; BLM, bleomycin; $\mathrm{VCR}$, vincristine; MMC, mitomycin

${ }^{*} \mathrm{CPT}-11,60 \mathrm{mg} / \mathrm{m}^{2}$; NDP, $80 \mathrm{mg} / \mathrm{m}^{2}$; every 3 weeks.

${ }^{*}$ PTX, $175 \mathrm{mg} / \mathrm{m}^{2}$; CDDP, $100 \mathrm{mg} / \mathrm{m}^{2}$; every 3 weeks.

${ }^{*} \mathrm{DTX}, 60 \mathrm{mg} / \mathrm{m}^{2}$; CBDCA, AUC = 6; every 3 weeks.

${ }^{*} \mathrm{PTX}, 80 \mathrm{mg} / \mathrm{m}^{2}$, days 1,8 , and 15 ; CDDP, $75 \mathrm{mg} / \mathrm{m}^{2}$, day 1 ; every 3 weeks.

${ }^{*}$ BLM: $5 \mathrm{mg} /$ body for 7 consecutive days; VCR, $0.7 \mathrm{mg} / \mathrm{m}^{2}$, day 7 ; MMC, $7 \mathrm{mg} / \mathrm{m}^{2}$, day 7; CDDP, $10 \mathrm{mg} / \mathrm{m}^{2}$, days $1-7$; every 4 weeks.

${ }^{*}$ PTX, $135 \mathrm{mg} / \mathrm{m}^{2}$ for $24 \mathrm{~h}$, day 1; CDDP, $50 \mathrm{mg} / \mathrm{m}^{2}$, day 2; every 4 weeks.

${ }^{* 7} \mathrm{PTX}, 175 \mathrm{mg} / \mathrm{m}^{2}$ (or DTX, $60 \mathrm{mg} / \mathrm{m}^{2}$ ); CBDCA, AUC = 6; every 3 weeks.

${ }^{*} \mathrm{PTX}, 175 \mathrm{mg} / \mathrm{m}^{2}$; NDP, $80 \mathrm{mg} / \mathrm{m}^{2}$; every 4 weeks.

*15-year disease-free survival. 
apy by decreasing pathological risk factors and distant metastasis but concluded that NAC followed by RH failed to improve survival compared to $\mathrm{RH}$ without NAC in patients with stage IB1-IIA UCC (Kim et al. 2013). Recently, at the American Society of Clinical Oncology annual meeting, the randomized phase III study (EORTC55994) compared NAC followed by RH (NACT) and cisplatin (CDDP)-based CCRT (C-CCRT) in 626 patients with stage IB2-IIB UCC between May 2002 and June 2014 (NACT, 314 patients; C-CCRT, 312 patients) (Kenter et al. 2019). With a median follow-up duration of 8 years, the 5-year OS was not significantly different between the NACT group and C-CCRT group (5-year OS rate, NACT vs. C-CCRT, $71.7 \%$ vs. $75.5 \%, p=0.297$ ). The 5 -year progression-free survival (PFS) was significantly longer in the CCRT group compared to that in the NACT group (5-year PFS rate, NACT vs. C-CCRT, $56.9 \%$ vs. $65.6 \% ; \mathrm{p}=0.021)$, but in patients who underwent protocolscheduled treatment, the difference was not significant (5-year PFS rate, NACT vs. C-CCRT, $61.8 \%$ vs. $67.7 \%$; $\mathrm{p}=$ $0.154)$.

Consequently, the strategy for NAC followed by RH needs a high response rate (RR) of NAC and high curability of RH. Since the JGOG study suggested that surgery at high-volume centers might be associated with decreased local recurrence risk and improved survival (Matsuo et al. 2019b), NAC followed by RH is the optional strategy for patients with stage IB3, IIA2, and IIB UCC at the appropriate institutions, such as high-volume centers. As a promising chemotherapeutic regimen of NAC, Tanioka et al. (2017) reported that dose-dense paclitaxel (PTX)/cisplatin (CDDP) (PTX, $80 \mathrm{mg} / \mathrm{m}^{2}$, day $1,8,15$; every 21 days, CDDP, $75 \mathrm{mg} / \mathrm{m}^{2}$, dayl) before and after RH in 51 patients with stage IB2, IIA2, and IIB UCC (FIGO 2014) showed a high pathological complete response (pCR) rate (RR, 94\%; pCR, 28\%), and 5-year OS was $88.2 \%$ in the phase II study.

A meta-analysis of 11 studies analyzed the impact of NAC followed by RH on clinical outcomes in patients with various histological subtypes of UCC (He et al. 2014). The 5 -year OS of patients with SCC was significantly better than of those with nSCC (HR, 1.47; 95\% CI, 1.06-2.06), suggesting that nSCC is less chemosensitive than SCC. Some previous retrospective studies reported that the RR of patients with nSCC to NAC was relatively lower, ranging from $50 \%$ to $67 \%$ (Lissoni et al. 1997; Iwasaka et al. 1998; Saito et al. 2004). Since nSCC is a relatively rare histological subtype, few prospective or randomized studies focusing on this rare disease revealed the most appropriate chemotherapeutic regimen for patients with nSCC of the uterine cervix. Shimada and coworkers (2016) conducted a phase II study to evaluate the efficacy of NAC with docetaxel (DTX) and carboplatin (CBDCA) followed by $\mathrm{RH}$ in 51 eligible patients with stage IB3, IIA2, and IIB nSCC. In this phase II study, DTX/CBDCA combination chemotherapy showed an RR of $69 \%$ (complete response, 5; partial response, 31; stable disease, 15; progressive dis- ease, 1) in the NAC setting. Recently, a JGOG nationwide retrospective cohort study evaluated the efficacy of the NAC regimen for various histological subtypes of stage IB-IIB UCC (Matsuo et al. 2019a). A JGOG study also reported that, among women who underwent NAC followed by $\mathrm{RH}$, the disease-free survival tended to be worse in patients with nSCC than those with SCC. In addition, the use of taxane/platinum combination chemotherapy regimens for NAC significantly increased between 2004 and 2008, but taxane/platinum regimens showed a similar effect on survival compared to non-taxane/platinum regimens.

\section{Definitive Radiotherapy as Primary Treatment for Patients with Stage IB-IIB UCC}

The mainstay treatment for locally advanced UCC is CCRT. Based on the results of landmark randomized trials, the NCCN guidelines mainly recommend CDDP-based CCRT as the most appropriate treatment for patients with stage IB3, IIA2, and IIB-IVA UCC, regardless of histological subtype (Keys et al. 1999; Rose et al. 1999; Whitney et al. 1999) (NCCN Guidelines ${ }^{\circledR}$ Cervical Cancer version 2.2020). Similar to the NCCN guideline, most guidelines do not subclassify treatment recommendation by histological subtype. As a result, a Cochrane systematic review revealed that CCRT reduced the mortality risk compared to conventional radiotherapy alone (HR, $0.81 ; 95 \%$ CI, 0.71 0.91 ) and improved the 5 -year OS rate by $6 \%$ in patients with locally advanced UCC (from $60 \%$ to $66 \%$ ) (CCCMAC, Chemoradiotherapy for Cervical Cancer MetaAnalysis Collaboration 2010).

It is still unknown whether the efficacy of CDDPbased CCRT for locally advanced patients with nSCC of the uterine cervix is similar to those with SCC. A GOG retrospective study including 1,489 patients with SCC and 182 patients with $\mathrm{nSCC}$ evaluated the efficacy of radiotherapy alone and CCRT by histological subtypes with clinical database of some GOG trials (Rose et al. 2014). Although patients with $\mathrm{nSCC}$ had significantly slightly worse OS than those with SCC in patients who underwent radiotherapy alone, CDDP-based CCRT improved OS of patients with nSCC and showed a similar outcome to that of patients with SCC. However, these GOG studies did not include the sufficient subjects of $\mathrm{nSCC}$, and chemotherapeutic regimen was not unified. Some authors suggested that radiosensitivity was poor in patients with nSCC (Niibe et al. 2010; Huang et al. 2011; Lee et al. 2015; Yokoi et al. 2017). The retrospective analysis by the national database in Korea reported that adenocarcinoma was still associated with worse OS compared to SCC in the era of CCRT (HR, 1.40; $95 \%$ CI, 1.30-1.50), although the survival of adenocarcinoma was improved after the introduction of CCRT (Lee et al. 2015). Thus, half of all Japanese gynecologic oncologists (53.7\%: 88/164) selected RH for patients with stage IIB nSCC, while one third (35.5\%: 59/164) selected RH for those with SCC (Mikami et al. 2014).

To further improve the efficacy of CDDP-based CCRT, 
which is basically used with CDDP at a dose of $40 \mathrm{mg} / \mathrm{m}^{2} /$ week, several authors investigated new CDDP-based CCRT by several combination chemotherapy regimens, along with changes in dose and timing (Dueñas-González et al. 2011; Umayahara et al. 2016; Chen et al. 2017). The randomized trial involving 515 patients with stage IIB-IVA UCC showed that CCRT with CDDP/gemcitabine (GEM) improved OS compared to conventional CDDP-based CCRT (HR, 0.68; 95\% CI, 0.49-0.95, p = 0.022) (DueñasGonzález et al. 2011). However, CCRT with CDDP/GEM also significantly increased severe hematologic toxicity and diarrhea. In addition, the optimal timing of CDDP/GEM during CCRT has been unclear, and CCRT with CDDP/ GEM is not currently recommended. Umayahara et al. (2016) conducted the phase study of CCRT with weekly CDDP at $30 \mathrm{mg} / \mathrm{m}^{2}$ and PTX at $50 \mathrm{mg} / \mathrm{m}^{2}$ in patients with stage III-IVA UCC (JACCRO GY-01). In 60 eligible patients, the complete RR was $76.5 \%$ (95\% CI, 66.4$86.6 \%$ ), and the 2-year cumulative PFS and OS rates were $83.8 \%$ (95\% CI, 75.1-92.6\%) and 92.7\% (95\% CI, 86.4$98.9 \%$ ), respectively (Umayahara et al. 2016). The 2-year cumulative late complication rate was $25 \%$ for all grades with $2.9 \%$ for grade 3 and $2.9 \%$ for grade 4 , suggesting that CCRT with weekly CDDP and PTX might be one of the alternative strategies for locally advanced patients with UCC. Evaluation of these new CDDP-based CCRT in the phase III trial is warranted to assess the efficacy of patients with nSCC of the uterine cervix.

\section{Adjuvant Treatment after RH}

Based on the histopathological findings of surgical specimens, patients were divided into three recurrent-risk groups: low-risk group, intermediate-risk group, and highrisk group in JSGO guidelines (Ebina et al. 2019). Patients in the low-risk group met all of the following criteria: small cervical tumor $(\leq 4 \mathrm{~cm})$, negative pelvic node involvement, negative parametrial invasion, shallow cervical stromal invasion, and absence of lymphovascular space invasion. Patients in the intermediate-risk group had negative pelvic node involvement and negative parametrial invasion but who met one of the following criteria: large cervical tumor $(>4 \mathrm{~cm})$, deep cervical stromal invasion, and positive lymphovascular space invasion. Patients in the high-risk group met one of the following criteria: positive pelvic node involvement and positive parametrial invasion. The JSGO treatment guideline recommended adjuvant radiotherapy, such as radiotherapy alone or CCRT, for patients in the intermediate-risk group and adjuvant CCRT with weekly CDDP at a dose of $40 \mathrm{mg} / \mathrm{m}^{2}$ for those in the high-risk group (Ebina et al. 2019).

Yessaian et al. (2004) reported that approximately 50\% of patients had intermediate-risk factors, approximately $40 \%$ of them had high-risk factors, and only $10 \%$ of them had no pathological recurrent risk factors among patients with stage IB2 UCC (FIGO 2008). Then, only approximately $10 \%$ of patients with stage IB2 (FIGO 2008) can be adequately treated with RH as an upfront single modality. The multimodality strategy consisting of RH followed by adjuvant radiotherapy is associated with not only impaired quality of life but also high cost. In addition, if patients have pelvic recurrence, they lose a useful treatment "radiotherapy" for recurrent disease in pelvis.

The significance of multimodality strategy consisting of chemotherapy before and after RH is evaluated (Angioli et al. 2012; Tanioka et al. 2017; Mori et al. 2019). These studies suggested a good outcome of multimodality strategy, which combined chemotherapy and $\mathrm{RH}$, in patients with stage IB2-IIB UCC. However, these studies were not randomized studies but just phase II studies that included relatively small numbers of patients with stage IB2-IIB disease.

\section{Adjuvant Radiotherapy after RH}

The JSGO guidelines recommend whole-pelvis irradiation, with a dose of 40-50 Gy (in fractions of 1.8-2.0 Gy/ day), as adjuvant treatment for intermediate/high-risk patients after RH (Ebina et al. 2019). The clinical target volume of whole pelvic radiotherapy includes the pelvic lymph node region, supravaginal region (from the vaginal stump to approximately $3 \mathrm{~cm}$ of the lower part), parametrial tissue, and paravaginal tissue. In patients with intermediate risk, radiation therapy or CCRT was recommended depending on the number of recurrent-risk factor.

The GOG092 study was a pivotal study that investigated the significance of radiotherapy alone for patients with intermediate-risk cervical cancer after RH (Sedlis et al. 1999). Adjuvant radiotherapy showed a 47\% reduction in the risk of recurrence compared to the absence of further adjuvant treatment. However, the improvement in OS with adjuvant radiotherapy did not reach statistical significance, while patients allocated to the adjuvant radiotherapy group had an increased incidence of severe toxicities compared with the no further adjuvant treatment group. Recently, Tsuchida et al. (2019) reported that intensity-modulated radiation therapy (IMRT) can reduce the radiation dose for normal tissues, including the small intestine, rectum, and bladder, used adjuvant irradiation. The Japan Clinical Oncology Group (JCOG) evaluated the efficacy and safety of IMRT as adjuvant treatment for high-risk patients in a nonrandomized confirmatory trial (JCOG 1402; jRCTs031180194).

In high-risk patients, CCRT with weekly CDDP at a dose of $40 \mathrm{mg} / \mathrm{m}^{2}$ was basically recommended as adjuvant treatment after RH. The landmark clinical trial of adjuvant irradiation for high-risk patients with UCC is the randomized phase III trial to determine whether the addition of CDDP/5-fluorouracil (FU) chemotherapy to pelvic irradiation can improve the survival of high-risk patients (Peters et al. 2000). In this phase III study, CCRT with CDDP/5-FU chemotherapy showed a significant improvement in PFS and OS of high-risk patients with UCC compared to pelvic irradiation alone. 
PTX and CDDP combination chemotherapy was reported to be more effective than CDDP alone for advanced/recurrent UCC (Moore et al. 2004). The JCOG also showed that PTX and CBDCA combination chemotherapy was non-inferior to PTX/CDDP chemotherapy for stage IVB and recurrent cervical cancer in the randomized phase III study (JCOG0505) (Kitagawa et al. 2015). Expecting to further improve the curative effect of CCRT for UCC, some authors evaluated the efficacy and safety of CCRT with PTX/CDDP or carboplatin (CBDCA) combination chemotherapy regimen. The phase II trial of IMRT with concurrent PTX/CDDP chemotherapy as adjuvant treatment for 67 patients with high-risk UCC demonstrated that the 4-year relapse-free survival, locoregional control, and distant failure rates were $92.9 \%, 98.0 \%$, and $5.2 \%$, respectively (Wang et al. 2015). After the evaluation of surgical specimens, patients underwent the first cycle of PTX/CDDP chemotherapy (PTX, $135 \mathrm{mg} / \mathrm{m}^{2}$; CDDP, 70 $\mathrm{mg} / \mathrm{m}^{2}$ ) before radiotherapy. With 3 weeks interval from the first systemic chemotherapy cycle, patients received the second and third cycles of PTX/CDDP chemotherapy (PTX, $90 \mathrm{mg} / \mathrm{m}^{2}$; CDDP, $50 \mathrm{mg} / \mathrm{m}^{2}$ ) every 3 weeks during IMRT. After 3-4 weeks from the end of IMRT, the fourth cycle of PTX/CDDP chemotherapy was administered. CCRT with PTX/CDDP chemotherapy may be one of the most effective adjuvant radiotherapy for patients with high-risk UCC.

The Japanese retrospective study reported that, among patients receiving adjuvant radiotherapy after $\mathrm{RH}$, patients with nSCC more frequently had recurrence compared to those with SCC, particularly in the pelvic cavity (Shimada et al. 2013a). In addition, a multi-institutional retrospective analysis of JCOG reported that gastric-type mucinous carcinoma (GAS) of the uterine cervix showed significantly higher resistance to postoperative radiotherapy compared to those with usual-type endocervical adenocarcinoma (UEA) $(50 \%, 6 / 12$ vs. $81.8 \%, 9 / 11 ; \mathrm{p}<0.0001$ ) (Nishio et al. 2019). Accordingly, a new adjuvant strategy, including molecular targeting therapy, is necessary for high-risk patients with non-SCC to reduce local recurrence and hematogenous distant metastasis as low as possible.

\section{Adjuvant Chemotherapy after RH}

Based on the evaluation of surgical-pathological information obtained from the surgical specimen, patients with pathological risk of recurrence were recommended to receive radiotherapy or CDDP-based CCRT as adjuvant treatment. In patients with stage IB3, IIA2, and IIB UCC (FIGO 2018), the NCCN guidelines mainly recommended CDDP-based CCRT as the most appropriate treatment based on the results of previous randomized phase III trials.

Eifel et al. (1995) suggested that adenocarcinoma had statistically significantly increased distant relapse rates compared with SCC regardless of tumor size in patients with stage IB disease receiving radiotherapy. Our previous study, which included 3,471 surgically treated patients with stage IB-IIB UCC, also suggested that non-SCC predomi- nantly recurred hematogenously, whereas SCC recurred lymphatically (Shimada et al. 2006). Adjuvant radiotherapy sometimes caused late adverse complications because of the anatomic locations, such as gastrointestinal complication, lower-limb lymphedema (Hosaka et al. 2008; Deura et al. 2015; Machida et al. 2019). Machida et al. (2019) reported that postoperative adjuvant chemotherapy increased the frequencies of bladder dysfunction after $\mathrm{RH}$ in patients with UCC by JGOG retrospective study. Thereby, many gynecologic oncologists in Japan also evaluated the superiority of adjuvant chemotherapy according to the complication rate (Ikeda et al. 2016). Several authors reported the efficacy of adjuvant chemotherapy in patients with intermediate/high risk of UCC after RH in Japan (Table 1) (Takeshima et al. 2006; Hosaka et al. 2012; Sato et al. 2016; Matoda et al. 2018; Takekuma et al. 2018). Sato et al. (2016) investigated the efficacy of adjuvant chemotherapy using taxane and CBDCA for patients with highrisk stage IB- IIB UCC after RH in their feasibility study. Of 37 eligible patients, 22 patients received PTX/CBDCA chemotherapy, and the remaining 15 patients received docetaxel (DTX)/CBDCA chemotherapy. With a median follow-up duration of 42.3 months, the 2-year PFS rate was $62.1 \%$ (95\% CI, 44.6-75.5\%). Patients receiving DTX/ CBDCA chemotherapy showed better 2-year PFS than those receiving PTX/CBDCA chemotherapy, but the difference was not statistically significant $(80.0 \%$ vs. $50.0 \%$, p = $0.14)$. Since the subjects of this feasibility study showed the worst outcome in patients who underwent $\mathrm{RH}$, taxane/ CBDCA combination chemotherapy, especially DTX/ CBDCA chemotherapy, was one of the alternative chemotherapeutic regimens as postoperative adjuvant chemotherapy in pathological-risk patients with $\mathrm{nSCC}$ (Sato et al. 2016).

The JGOG retrospective cohort study examined survival of 555 women with stage IB disease in the intermediate-risk group (large tumor size $>4 \mathrm{~cm}$, deep stromal invasion $>50 \%$, lymphovascular space invasion) by adjuvant treatment patterns: chemotherapy alone $(\mathrm{n}=223,40.2 \%)$, CCRT $(\mathrm{n}=172,31.0 \%)$, and radiotherapy alone $(\mathrm{n}=160$, 28.8\%) (Matsuo et al. 2017b). The most preferred chemotherapy regimen was taxane/platinum combination chemotherapy $(52.2 \%)$. Women with $\mathrm{nSCC}$ were more likely to receive chemotherapy compared to those with SCC. Women who received adjuvant chemotherapy showed similar disease-free survival, cause-specific survival, cumulative local recurrence, and distant recurrence compared to those who received other adjuvant treatments, such as CCRT and radiotherapy alone. In another JGOG retrospective cohort study examining 1,074 women with pelvic node-positive stage IB-IIB cervical cancer who underwent RH, women who received adjuvant chemotherapy had similar survival outcomes compared to those who received CCRT (Matsuo et al. 2017a). However, systematic chemotherapy and irradiation had distinct recurrence patterns. While systematic chemotherapy was associated with increased risk of local 
recurrence compared to CCRT, systematic chemotherapy was associated with decreased risk of distant recurrence compared to CCRT. Consequently, the higher curability with RH, such as the Okabayashi's RH, is indispensable for adjuvant chemotherapy in high-risk patients with UCC.

Since there is no prospective randomized study to compare chemotherapy and CCRT as adjuvant treatment for intermediate/high-risk patients who underwent $\mathrm{RH}$, validity of postoperative chemotherapy is not yet confirmed. Consequently, the JSGO guidelines 2017 did not describe the recommendation of adjuvant chemotherapy for intermediate/high-risk patients with cervical cancer (Ebina et al. 2019). The JGOG conducted the randomized phase III study to investigate the efficacy and safety of adjuvant chemotherapy for patients with high-risk cervical cancer compared to those of CDDP-based CCRT (JGOG1082; jRCTs041190042).

\section{GAS of the Uterine Cervix}

GAS of the uterine cervix is a relatively newly recognized variant of endocervical adenocarcinoma initially described by Japanese groups (Ishii et al. 1998; Mikami et al. 2004; Kojima et al. 2007) and was included as a subtype of endocervical mucinous adenocarcinoma in the World Health Organization (WHO) classification updated in 2014 (Kurman et al. 2014). It is defined as a mucinous carcinoma showing gastric-type differentiation, including minimal deviation adenocarcinoma (so-called adenoma malignum) in its morphologic spectrum. In contrast to UEA, GAS is frequently located in the upper endocervix and shows a bulky cervix without well-demarcated mass due to its highly infiltrating pattern of growth. While most UEAs are mostly related to human papillomavirus (HPV), GAS is reported to be unrelated to HPV (Mikami 2020) and importantly is associated with aggressive clinical behavior, and its outcome is worse than UEA (Kojima et al. 2007; Kusanagi et al. 2010; Houghton et al. 2010; Park et al. 2011; Karamurzin et al. 2015; Nishio et al. 2019). Of 328 eligible patients with endocervical adenocarcinoma in the JCOG retrospective study, 95 cases were reclassified as GAS by a central pathological review (Nishio et al. 2019). Compared to UAE, GAS was more significantly associated with bulky mass, deep stromal invasion, lymphovasucular space invasion, parametrial invasion, ovarian metastasis, positive peritoneal cytology, pelvic lymph node involvement, and pathological $\mathrm{T}$ stage. Disease-free survival and OS were also poorer in patients with GAS than in those with UEA.

Kojima et al. (2018) evaluated the chemosensitivity of GAS compared with UEA in a subgroup of patients who had enrolled in their previous phase II study (Shimada et al. 2016) to investigate the efficacy of DTX/CBDCA combination chemotherapy in patients with stage IB3, IIA2, and IIB $\mathrm{nSCC}$ of the uterine cervix. Of 47 patients with $\mathrm{nSCC}$ who could be reevaluated by central pathological review, 20 (42.6\%) were diagnosed with UEA, 13 (27.7\%) with GAS, and the remaining 14 were diagnosed with other histological subtypes (12, adenosquamous carcinoma; 1, small-cell carcinoma; and 1, serous carcinoma). The RR of GAS was significantly lower than that of UEA ( $46.2 \%$ vs. $85.0 \%$, p = $0.048)$. Of 16 patients with stage II UEA, $11(68.8 \%)$ were down-staged on microscopic examination of postsurgical specimens, but none of the 8 patients with stage II GAS showed any response $(\mathrm{p}<0.01)$, and two inoperative tumors were diagnosed as GAS in the previous phase II study (Kojima et al. 2018).

In addition, the subset analysis of a JCOG study suggested that patients with GAS showed significantly higher resistance to radiotherapy compared with those with UEA (Nishio et al. 2019). Taken together, GAS may be resistant to both chemotherapy and radiotherapy compared to UEA. To achieve better oncologic outcome for patients with locally advanced aggressive UCC, such as GAS, various multidisciplinary therapeutic strategies incorporating cisplatin-based CCRT and molecular targeting therapy have been investigated. However, profiles of genomic signature of unusual UCC, represented by GAS, clear cell carcinoma, and serous carcinoma, are still limited, and definite treatment guideline for such cancers remains to be established.

\section{Survival by Histological Subtype in Patients with UCC}

Some retrospective studies assessed the impact of histological type on survival outcome of UCC (Irie et al. 2000; Kasamatsu et al. 2009; Katanyoo et al. 2012; Galic et al. 2012; Shimada et al. 2013b; Seamon et al. 2018), but these studies have limitations, including lack of critical central pathology review, stratification by pathological prognostic factors, or information on management and low incidence of GAS in the series. In contrast, by focusing on histologic subtype, Kojima et al. (2018) demonstrated that patients with stage IB2-IIB UEA showed a high RR of $85 \%$ to DTX/CBDCA combination chemotherapy in the phase II study. All patients with UEA underwent RH after NAC and showed a favorable outcome in a similar degree to that in patients with SCC with the matched stage, while GAS showed clearly poorer prognosis. UEA is the most common form of endocervical adenocarcinoma, accounting for $80-90 \%$ of all adenocarcinomas of the cervix in many countries. Before the concept and diagnostic criteria of GAS were proposed, most GASs had been categorized into endocervical-type mucinous adenocarcinoma according the WHO 2003 classification (Mikami et al. 2004; Kusanagi et al. 2010). Although GAS is considered rare in Western countries (Holl et al. 2015), it is rather common in Japan, accounting for up to $20-25 \%$ of all endocervical adenocarcinomas (Kojima et al. 2007; Kusanagi et al. 2010). Under such a condition, it might affect the prognosis interpretation of the whole adenocarcinoma that there was a regional difference in the GAS frequency (Kojima et al. 2007; Kusanagi et al. 2010; Holl et al. 2015). Machida et al. (2020) also evaluated survival outcome in patients with cer- 
vical adenocarcinoma subtype by two grouping as following: type 1 (endocervical usual type and endometrioid) and type 2 (serous, clear, mucinous, and not otherwise specified), using JSGO tumor registry database. They reported that patients with type 2 adenocarcinoma showed significantly worse survival compared with those with SCC (adjusted hazard ratio 2.00, 95\% CI 1.84-2.15, $\mathrm{p}<0.001$ ). Consequently, after controlling for prognostic pathological factors and clinical management, the survival outcome of the majority of patients with adenocarcinoma largely depends on relative incidence of UEA and GAS. In our hypothesis, prognosis of adenocarcinoma may be equivalent to that of patients with matched SCC among a series in which UEA is common, whereas it is not in areas where GAS is relatively common. The latest annual report of JSOG revealed that there were 142 patients with GAS (8.9\%) in 2018 among 1,591 patients with endocervical adenocarcinoma (Yaegashi 2020). In contrast, Holl et al. (2015) reported that of 461 cases of cervical adenocarcinoma, there were only 7 patients with GAS (1.5\%) in 17 European countries between November 2006 and August 2008.

\section{Biological Variables by Histological Subtypes in Patients with UCC}

IECC proposed to categorize endocervical adenocarcinoma two groups (HPVA and NHPVA) by HPV infection status. Patients with HPVA, including UEA, showed less lymphvasucular invasion and lymph node metastasis, better response to conventional treatment, and better survival outcome compared to those with NHPVA, such as GAS (Kojima et al. 2018; Stolnicu et al. 2018, 2019), suggesting that HPV infection status might be a useful clinical biomarker for patients with UCC.

Low expression of p16, p21, and p27 was reported as biomarkers of adenocarcinoma of the uterine cervix ( $\mathrm{Lu}$ et al. 1998; Alfsen et al. 2003). Low p27 expression and high p16 expression were strongly associated with poor prognosis of adenocarcinoma (Alfsen et al. 2003), and p21 expression was also an independent predictor of good clinical outcome (Lu et al. 1998). Tornesello et al. (2013) reported that patients with adenocarcinoma showed significantly higher p53 mutation than those with SCC in a systematic review of 27 studies, but it is still unclear whether the p53 mutational status is associated with clinical outcome of patients with UCC (Tsuda et al. 1995; Lu et al. 1998; Tornesello et al. 2014).

Ueda et al. (2017) examined the expression profile of epidermal growth factor receptor (EGFR), human EGFRrelated 2 (HER2), and c-Met in 43 specimens from patients with adenocarcinoma. Double positive expression of EGFR and HER2 correlated with lymph node metastasis, advanced stage, and worse disease-free survival (Ueda et al. 2017). Nakamura et al. (2019) reported that HER2 expression status was equivocal in 6 of 13 patients with GAS by immunohistochemistry, and HER2 amplification was identified in 1 patient with GAS.

Maspin is a member of the serpin family of protease inhibitors, and its cytoplasmic expression is associated with poorer clinical outcome in several malignancies (Umekita et al. 2002; Takagi et al. 2015). Nosaka et al. (2015) reported that positive immunostaining for maspin in $69.2 \%$ of 46 patients with adenocarcinoma of the uterine cervix and demonstrated that maspin-positive cases showed significantly worse 5-year PFS and OS than maspin-negative cases.

\section{Conclusion}

The impact of histological type on survival outcome of UCC is controversial. However, in our hypothesis, the difference in survival outcome by histological subtype might be remarkable with disease progression, and the survival outcome of nSCC might be deeply affected by regional difference in the frequency of GAS of the uterine cervix.

The HPV vaccination program and cytological examination combined with screening testing for HPV were expected to prevent UCC. However, it is still uncertain whether HPV vaccination prevents UCC as trials were not designed to detect this outcome (Rees et al. 2020). In addition, under the circumstance, there are no useful strategies for refractory and uncommon UCC, such as GAS, which is not associated with HPV infection. To achieve better oncologic outcome for patients with locally advanced aggressive, refractory UCC, such as GAS, various multidisciplinary therapeutic strategies incorporating high-quality RH, CDDP-based CCRT, and molecular targeting therapy should be investigated. Unfortunately, profiles of genomic signature of unusual UCC, represented by GAS, clear cell carcinoma, and serous carcinoma, are still unknown. The integrated analysis including genomic profiles for these unusual, refractory UCC should be performed by an international joint research network, such as the Gynecologic Cancer InterGroup.

\section{Conflict of Interest}

The authors declare no conflict of interest.

\section{References}

Alfsen, G.C., Reed, W., Sandstad, B., Kristensen, G.B. \& Abeler, V.M. (2003) The prognostic impact of cyclin dependent kinase inhibitors p21WAF1, p27Kip1, and p16INK4/MTS1 in adenocarcinomas of the uterine cervix: an immunohistochemical evaluation of expression patterns in population-based material from 142 patients with international federation of gynecology and obstetrics stage I and II adenocarcinoma. Cancer, 98, 1880-1889.

Angioli, R., Plotti, F., Montera, R., Aloisi, A., Luvero, D., Capriglione, S., Terranova, C., De Cicco Nardone, C., Muzii, L. \& Benedetti-Panici, P. (2012) Neoadjuvant chemotherapy plus radical surgery followed by chemotherapy in locally advanced cervical cancer. Gynecol. Oncol., 127, 290-296.

Arbyn, M., Weiderpass, E., Bruni, L., de Sanjosé, S., Saraiya, M., Ferlay, J. \& Bray, F. (2020) Estimates of incidence and mortality of cervical cancer in 2018: a worldwide analysis. Lancet Glob. Health, 8, e191-e203. 
Chemoradiotherapy for Cervical Cancer Meta-Analysis Collaboration (CCCMAC) (2010) Reducing uncertainties about the effects of chemoradiotherapy for cervical cancer: individual patient data meta-analysis. Cochrane Database Syst. Rev., 2010, CD008285.

Chen, X., Zou, H., Li, H., Lin, R., Su, M., Zhang, W., Zhou, Y., Zhang, P., Hou, M., Deng, X. \& Zou, C. (2017) Weekly versus triweekly cisplatin-based chemotherapy concurrent with radiotherapy in the treatment of cervical cancer: a metaanalysis. Int. J. Gynecol. Cancer, 27, 344-349.

Deura, I., Shimada, M., Hirashita, K., Sugimura, M., Sato, S., Sato, S., Oishi, T., Itamochi, H., Harada, T. \& Kigawa, J. (2015) Incidence and risk factors for lower limb lymphedema after gynecologic cancer surgery with initiation of periodic complex decongestive physiotherapy. Int. J. Clin. Oncol., 20, 556-560.

Dueñas-González, A., Zarbá, J.J., Patel, F., Alcedo, J.C., Beslija, S., Casanova, L., Pattaranutaporn, P., Hameed, S., Blair, J.M., Barraclough, H. \& Orlando, M. (2011) Phase III, open-label, randomized study comparing concurrent gemcitabine plus cisplatin and radiation followed by adjuvant gemcitabine and cisplatin versus concurrent cisplatin and radiation in patients with stage IIB to IVA carcinoma of the cervix. J. Clin. Oncol., 29, 1678-1685.

Ebina, Y., Mikami, M., Nagase, S., Tabata, T., Kaneuchi, M., Tashiro, H., Mandai, M., Enomoto, T., Kobayashi, Y., Katabuchi, H., Yaegashi, N., Udagawa, Y. \& Aoki, D. (2019) Japan Society of Gynecologic Oncology guidelines 2017 for the treatment of uterine cervical cancer. Int. J. Clin. Oncol., 24, 1-19.

Eddy, G.L., Bundy, B.N., Creasman, W.T., Spirtos, N.M., Mannel, R.S., Hannigan, E. \& O'Connor, D. (2007) Treatment of ("bulky") stage IB cervical cancer with or without neoadjuvant vincristine and cisplatin prior to radical hysterectomy and pelvic/para-aortic lymphadenectomy: a phase III trial of the gynecologic oncology group. Gynecol. Oncol., 106, 362-369.

Eifel, P.J., Burke, T.W., Morris, M. \& Smith, T.L. (1995) Adenocarcinoma as an independent risk factor for disease recurrence in patients with stage IB cervical carcinoma. Gynecol. Oncol., 59, 38-44.

Galic, V., Herzog, T.J., Lewin, S.N., Neugut, A.I., Burke, W.M., Lu, Y.S., Hershman, D.L. \& Wright, J.D. (2012) Prognostic significance of adenocarcinoma histology in women with cervical cancer. Gynecol. Oncol., 125, 287-291.

He, L., Wu, L., Su, G., Wei, W., Liang, L., Han, L., Kebria, M., Liu, P., Chen, C., Yu, Y., Zhong, M. \& Wang, W. (2014) The efficacy of neoadjuvant chemotherapy in different histological types of cervical cancer. Gynecol. Oncol., 134, 419-425.

Holl, K., Nowakowski, A.M., Powell, N., McCluggage, W.G., Pirog, E.C., Collas De Souza, S., Tjalma, W.A., Rosenlund, M., Fiander, A., Castro Sánchez, M., Damaskou, V., Joura, E.A., Kirschner, B., Koiss, R., O’Leary, J., et al. (2015) Human papillomavirus prevalence and type-distribution in cervical glandular neoplasias: results from a European multinational epidemiological study. Int. J. Cancer, 137, 28582868.

Hosaka, M., Watari, H., Takeda, M., Moriwaki, M., Hara, Y., Todo, Y., Ebina, Y. \& Sakuragi, N. (2008) Treatment of cervical cancer with adjuvant chemotherapy versus adjuvant radiotherapy after radical hysterectomy and systematic lymphadenectomy. J. Obstet. Gynaecol. Res., 34, 552-556.

Hosaka, M., Watari, H., Kato, T., Odagiri, T., Konno, Y., Endo, D., Mitamura, T., Kikawa, S., Suzuki, Y. \& Sakuragi, N. (2012) Clinical efficacy of paclitaxel/cisplatin as an adjuvant chemotherapy for patients with cervical cancer who underwent radical hysterectomy and systematic lymphadenectomy. $J$. Surg. Oncol., 105, 612-616.

Houghton, O., Jamison, J., Wilson, R., Carson, J. \& McCluggage, W.G. (2010) p16 Immunoreactivity in unusual types of cervical adenocarcinoma does not reflect human papilloma- virus infection. Histopathology, 57, 342-350.

Huang, Y.T., Wang, C.C., Tsai, C.S., Lai, C.H., Chang, T.C., Chou, H.H., Hsueh, S., Chen, C.K., Lee, S.P. \& Hong, J.H. (2011) Long-term outcome and prognostic factors for adenocarcinoma/adenosquamous carcinoma of cervix after definitive radiotherapy. Int. J. Radiat. Oncol. Biol. Phys., 80, 429-436.

Ikeda, Y., Furusawa, A., Kitagawa, R., Tokinaga, A., Ito, F., Ukita, M., Nomura, H., Yamagami, W., Tanabe, H., Mikami, M., Takeshima, N. \& Yaegashi, N. (2016) Practice patterns of adjuvant therapy for intermediate/high recurrence risk cervical cancer patients in Japan. J. Gynecol. Oncol., 27, e29.

Irie, T., Kigawa, J., Minagawa, Y., Itamochi, H., Sato, S., Akeshima, R. \& Terakawa, N. (2000) Prognosis and clinicopathological characteristics of Ib-IIb adenocarcinoma of the uterine cervix in patients who have had radical hysterectomy. Eur. J. Surg. Oncol., 26, 464-467.

Ishii, K., Hosaka, N., Toki, T., Momose, M., Hidaka, E., Tsuchiya, S. \& Katsuyama, T. (1998) A new view of the so-called adenoma malignum of the uterine cervix. Virchows Arch., 432, 315-322.

Iwasaka, T., Fukuda, K., Hara, K., Yokoyama, M., Nakao, Y., Uchiyama, M. \& Sugimori, H. (1998) Neoadjuvant chemotherapy with mitomycin $\mathrm{C}$, etoposide, and cisplatin for adenocarcinoma of the cervix. Gynecol. Oncol., 70, 236-240.

Karamurzin, Y.S., Kiyokawa, T., Parkash, V., Jotwani, A.R., Patel, P., Pike, M.C., Soslow, R.A. \& Park, K.J. (2015) Gastric-type endocervical adenocarcinoma: an aggressive tumor with unusual metastatic patterns and poor prognosis. Am. J. Surg. Pathol., 39, 1449-1457.

Kasamatsu, T., Onda, T., Sawada, M., Kato, T., Ikeda, S., Sasajima, Y. \& Tsuda, H. (2009) Radical hysterectomy for FIGO stage I-IIB adenocarcinoma of the uterine cervix. Br. J. Cancer, 100, 1400-1405.

Katanyoo, K., Sanguanrungsirikul, S. \& Manusirivithaya, S. (2012) Comparison of treatment outcomes between squamous cell carcinoma and adenocarcinoma in locally advanced cervical cancer. Gynecol. Oncol., 125, 292-296.

Kenter, G., Greggi, S., Vergote, I., Katsaros, D., Kobierski, J., Massuger, L., van Doorn, H.C., Landoni, F., Van Der Velden, J., Read, N.S,, Coens, C., van Luijk, I., Ottevanger, P.B. \& Casado A. (2019) Results from neoadjuvant chemotherapy followed by surgery compared to chemoradiation for stage Ib2-IIb cervical cancer, EORTC 55994. J. Clin. Oncol., 37 Suppl, 5503.

Keys, H.M., Bundy, B.N., Stehman, F.B., Muderspach, L.I., Chafe, W.E., Suggs, C.L. 3rd, Walker, J.L. \& Gersell, D. (1999) Cisplatin, radiation, and adjuvant hysterectomy compared with radiation and adjuvant hysterectomy for bulky stage IB cervical carcinoma. N. Engl. J. Med., 340, 1154-1161.

Kim, H.S., Sardi, J.E., Katsumata, N., Ryu, H.S., Nam, J.H., Chung, H.H., Park, N.H., Song, Y.S., Behtash, N., Kamura, T., Cai, H.B. \& Kim, J.W. (2013) Efficacy of neoadjuvant chemotherapy in patients with FIGO stage IB1 to IIA cervical cancer: an international collaborative meta-analysis. Eur. J. Surg. Oncol., 39, 115-124.

Kitagawa, R., Katsumata, N., Shibata, T., Kamura, T., Kasamatsu, T., Nakanishi, T., Nishimura, S., Ushijima, K., Takano, M., Satoh, T. \& Yoshikawa, H. (2015) Paclitaxel plus carboplatin versus paclitaxel plus cisplatin in metastatic or recurrent cervical cancer: the open-label randomized phase III trial JCOG0505. J. Clin. Oncol., 33, 2129-2135.

Kojima, A., Mikami, Y., Sudo, T., Yamaguchi, S., Kusanagi, Y., Ito, M. \& Nishimura, R. (2007) Gastric morphology and immunophenotype predict poor outcome in mucinous adenocarcinoma of the uterine cervix. Am. J. Surg. Pathol., 31, 664-672.

Kojima, A., Shimada, M., Mikami, Y., Nagao, S., Takeshima, N., Sugiyama, T., Teramoto, N., Kiyokawa, T., Kigawa, J. \& Nishimura, R.; Sankai Gynecology Study Group (2018) Chemoresistance of gastric-type mucinous carcinoma of the 
uterine cervix: a study of the Sankai Gynecology Study Group. Int. J. Gynecol. Cancer, 28, 99-106.

Kuragaki, C., Enomoto, T., Ueno, Y., Sun, H., Fujita, M., Nakashima, R., Ueda, Y., Wada, H., Murata, Y., Toki, T., Konishi, I. \& Fujii, S. (2003) Mutations in the STK11 gene characterize minimal deviation adenocarcinoma of the uterine cervix. Lab. Invest., 83, 35-45.

Kurman, R.J., Carcangiu, M.L., Herrington, C.S. \& Young, R.H. (2014) WHO classification of tumours of female reproductive organs, 4th ed., International Agency for Research on Cancer, Lyon, France.

Kusanagi, Y., Kojima, A., Mikami, Y., Kiyokawa, T., Sudo, T., Yamaguchi, S. \& Nishimura, R. (2010) Absence of high-risk human papillomavirus (HPV) detection in endocervical adenocarcinoma with gastric morphology and phenotype. Am. J. Pathol., 177, 2169-2175.

Lee, J.Y., Kim, Y.T., Kim, S., Lee, B., Lim, M.C., Kim, J.W. \& Won, Y.J. (2015) Prognosis of cervical cancer in the era of concurrent chemoradiation from national database in Korea: a comparison between squamous cell carcinoma and adenocarcinoma. PLoS One, 10, e0144887.

Lissoni, A., Gabriele, A., Gorga, G., Tumolo, S., Landoni, F., Mangioni, C. \& Sessa, C. (1997) Cisplatin-, epirubicin- and paclitaxel-containing chemotherapy in uterine adenocarcinoma. Ann. Oncol., 8, 969-972.

Lu, X., Toki, T., Konishi, I., Nikaido, T. \& Fujii, S. (1998) Expression of $\mathrm{p} 21 \mathrm{WAF} 1 / \mathrm{CIP} 1$ in adenocarcinoma of the uterine cervix: a possible immunohistochemical marker of a favorable prognosis. Cancer, 82, 2409-2417.

Machida, H., Matsuo, K., Furusawa, A., Kita, T., Kitagawa, R. \& Mikami, M. (2019) Profile of treatment-related complications in women with clinical stage IB-IIB cervical cancer: a nationwide cohort study in Japan. PLoS One, 14, e0210125.

Machida, H., Matsuo, K., Matsuzaki, S., Yamagami, W., Ebina, Y., Kobayashi, Y., Tabata, T., Kaneuchi, M., Nagase, S., Enomoto, T. \& Mikami, M. (2020) Proposal of a two-tier system in grouping adenocarcinoma of the uterine cervix. Cancers (Basel), 12, 1251.

Matoda, M., Takeshima, N., Michimae, H., Iwata, T., Yokota, H., Torii, Y., Yamamoto, Y., Takehara, K., Nishio, S., Takano, H., Mizuno, M., Takahashi, Y., Takei, Y., Hasegawa, T., Mikami, M., et al. (2018) Postoperative chemotherapy for node-positive cervical cancer: results of a multicenter phase II trial (JGOG1067). Gynecol. Oncol., 149, 513-519.

Matsuo, K., Shimada, M., Aoki, Y., Sakamoto, M., Takeshima, N., Fujiwara, H., Matsumoto, T., Mikami, M. \& Sugiyama, T. (2017a) Comparison of adjuvant therapy for node-positive clinical stage IB-IIB cervical cancer: systemic chemotherapy versus pelvic irradiation. Int. J. Cancer, 141, 1042-1051.

Matsuo, K., Shimada, M., Yokota, H., Satoh, T., Katabuchi, H., Kodama, S., Sasaki, H., Matsumura, N., Mikami, M. \& Sugiyama, T. (2017b) Effectiveness of adjuvant systemic chemotherapy for intermediate-risk stage IB cervical cancer. Oncotarget, 8, 106866-106875.

Matsuo, K., Shimada, M., Yamaguchi, S., Kigawa, J., Tokunaga, H., Tabata, T., Kodama, J., Kawana, K., Mikami, M. \& Sugiyama, T. (2019a) Neoadjuvant chemotherapy with taxane and platinum followed by radical hysterectomy for stage IB2-IIB cervical cancer: impact of histology type on survival. J. Clin. Med., 8, 156.

Matsuo, K., Shimada, M., Yamaguchi, S., Matoda, M., Nakanishi, T., Kikkawa, F., Ohmichi, M., Okamoto, A., Sugiyama, T. \& Mikami, M. (2019b) Association of radical hysterectomy surgical volume and survival for early-stage cervical cancer. Obstet. Gynecol., 133, 1086-1098.

Mikami, M., Aoki, Y., Sakamoto, M., Shimada, M., Takeshima, N., Fujiwara, H., Matsumoto, T., Kita, T. \& Takizawa, K.; Disease Committee of Uterine Cervical and Vulvar Cancer, Japanese Gynecologic Oncology Group (2014) Surgical principles for managing stage IB2, IIA2, and IIB uterine cervical cancer (Bulky Tumors) in Japan: a survey of the Japanese Gynecologic Oncology Group. Int. J. Gynecol. Cancer, 24, 13331340.

Mikami, M., Shida, M., Shibata, T., Katabuchi, H., Kigawa, J., Aoki, D. \& Yaegashi, N. (2018) Impact of institutional accreditation by the Japan Society of Gynecologic Oncology on the treatment and survival of women with cervical cancer. J. Gynecol. Oncol., 29, e23.

Mikami, Y. (2020) Gastric-type mucinous carcinoma of the cervix and its precursors: historical overview. Histopathology, 76, 102-111.

Mikami, Y., Kiyokawa, T., Hata, S., Fujiwara, K., Moriya, T., Sasano, H., Manabe, T., Akahira, J., Ito, K., Tase, T., Yaegashi, N., Sato, I., Tateno, H. \& Naganuma, H. (2004) Gastrointestinal immunophenotype in adenocarcinomas of the uterine cervix and related glandular lesions: a possible link between lobular endocervical glandular hyperplasia/pyloric gland metaplasia and 'adenoma malignum'. Mod. Pathol., 17, 962-972.

Moore, D.H., Blessing, J.A., McQuellon, R.P., Thaler, H.T., Cella, D., Benda, J., Miller, D.S., Olt, G., King, S., Boggess, J.F. \& Rocereto, T.F. (2004) Phase III study of cisplatin with or without paclitaxel in stage IVB, recurrent, or persistent squamous cell carcinoma of the cervix: a gynecologic oncology group study. J. Clin. Oncol., 22, 3113-3119.

Mori, T., Makino, H., Okubo, T., Fujiwara, Y., Sawada, M., Kuroboshi, H., Tsubamoto, H., Murakoshi, H., Motohashi, T., Kitawaki, J. \& Ito, K. (2019) Multi-institutional phase II study of neoadjuvant irinotecan and nedaplatin followed by radical hysterectomy and the adjuvant chemotherapy for locally advanced, bulky uterine cervical cancer: a Kansai Clinical Oncology Group study (KCOG-G1201). J. Obstet. Gynaecol. Res., 45, 671-678.

Nakamura, A., Yamaguchi, K., Minamiguchi, S., Murakami, R., Abiko, K., Hamanishi, J., Kondoh, E., Baba, T., Mandai, M. \& Matsumura, N. (2019) Mucinous adenocarcinoma, gastric type of the uterine cervix: clinical features and HER2 amplification. Med. Mol. Morphol., 52, 52-59.

National Comprehensive Cancer Network ${ }^{\circledR}$ (NCCN) (2020) Clinical Practice Guidelines in Oncology (NCCN Guidelines ${ }^{\circledR}$ ) Cervical Cancer NCCN Evidence BlocksTM Version 2.2020August 14, 2020.

https://www.nccn.org/professionals/physician_gls/pdf/ cervical_blocks.pdf

[Accessed: October 6, 2020].

Niibe, Y., Kenjo, M., Onishi, H., Ogawa, Y., Kazumoto, T., Ogino, I., Tsujino, K., Harima, Y., Takahashi, T., Anbai, A., Tsuchida, E., Toita, T., Takemoto, M., Yamashita, H. \& Hayakawa, K. (2010) High-dose-rate intracavitary brachytherapy combined with external beam radiotherapy for stage IIIb adenocarcinoma of the uterine cervix in Japan: a multi-institutional study of Japanese Society of Therapeutic Radiology and Oncology 2006-2007 (study of JASTRO 2006-2007). Jpn. J. Clin. Oncol., 40, 795-799.

Nishio, S., Mikami, Y., Tokunaga, H., Yaegashi, N., Satoh, T., Saito, M., Okamoto, A., Kasamatsu, T., Miyamoto, T., Shiozawa, T., Yoshioka, Y., Mandai, M., Kojima, A., Takehara, K., Kaneki, E., et al. (2019) Analysis of gastric-type mucinous carcinoma of the uterine cervix: an aggressive tumor with a poor prognosis: a multi-institutional study. Gynecol. Oncol., 153, 13-19.

Nosaka, K., Horie, Y., Shiomi, T., Itamochi, H., Oishi, T., Shimada, M., Sato, S., Sakabe, T., Harada, T. \& Umekita, Y. (2015) Cytoplasmic maspin expression correlates with poor prognosis of patients with adenocarcinoma of the uterine cervix. Yonago Acta Med., 58, 151-156.

Ojesina, A.I., Lichtenstein, L., Freeman, S.S., Pedamallu, C.S., Imaz-Rosshandler, I., Pugh, T.J., Cherniack, A.D., Ambrogio, 
L., Cibulskis, K., Bertelsen, B., Romero-Cordoba, S., Trevino, V., Vazquez-Santillan, K., Guadarrama, A.S., Wright, A.A., et al. (2014) Landscape of genomic alterations in cervical carcinomas. Nature, 506, 371-375.

Park, K.J., Kiyokawa, T., Soslow, R.A., Lamb, C.A., Oliva, E., Zivanovic, O., Juretzka, M.M. \& Pirog, E.C. (2011) Unusual endocervical adenocarcinomas: an immunohistochemical analysis with molecular detection of human papillomavirus. Am. J. Surg. Pathol., 35, 633-646.

Peters, W.A. 3rd, Liu, P.Y., Barrett, R.J. 2nd, Stock, R.J., Monk, B.J., Berek, J.S., Souhami, L., Grigsby, P., Gordon, W. Jr. \& Alberts, D.S. (2000) Concurrent chemotherapy and pelvic radiation therapy compared with pelvic radiation therapy alone as adjuvant therapy after radical surgery in high-risk earlystage cancer of the cervix. J. Clin. Oncol., 18, 1606-1613.

Quinn, M.A., Benedet, J.L., Odicino, F., Maisonneuve, P., Beller, U., Creasman, W.T., Heintz, A.P., Ngan, H.Y. \& Pecorelli, S. (2006) Carcinoma of the cervix uteri. FIGO 26th annual report on the results of treatment in gynecological cancer. Int. J. Gynaecol. Obstet., 95 Suppl 1, S43-103.

Rees, C.P., Brhlikova, P. \& Pollock, A.M. (2020) Will HPV vaccination prevent cervical cancer? J. R. Soc. Med., 113, 64-78.

Rose, P.G., Bundy, B.N., Watkins, E.B., Thigpen, J.T., Deppe, G., Maiman, M.A., Clarke-Pearson, D.L. \& Insalaco, S. (1999) Concurrent cisplatin-based radiotherapy and chemotherapy for locally advanced cervical cancer. N. Engl. J. Med., 340, 11441153.

Rose, P.G., Java, J.J., Whitney, C.W., Stehman, F.B., Lanciano, R. \& Thomas, G.M. (2014) Locally advanced adenocarcinoma and adenosquamous carcinomas of the cervix compared to squamous cell carcinomas of the cervix in gynecologic oncology group trials of cisplatin-based chemoradiation. Gynecol. Oncol., 135, 208-212.

Saito, T., Takehara, M., Lee, R., Fujimoto, T., Nishimura, M., Tanaka, R., Ito, E., Adachi, K. \& Kudo, R. (2004) Neoadjuvant chemotherapy with cisplatin, aclacinomycin A, and mitomycin $\mathrm{C}$ for cervical adenocarcinoma: a preliminary study. Int. J. Gynecol. Cancer, 14, 483-490.

Sato, S., Shimada, M., Ohta, T., Kojimahara, T., Tokunaga, H., Takano, T., Yamaguchi, S., Tanabe, H., Nishio, S. \& Kigawa, J. (2016) Feasibility study of adjuvant chemotherapy using taxane plus carboplatin for high-risk patients with uterine cervical non-squamous cell carcinoma after radical hysterectomy. Int. J. Gynecol. Cancer, 26, 561-567.

Seamon, L.G., Java, J.J., Monk, B.J., Penson, R.T., Brown, J., Mannel, R.S., Oaknin, A., Leitao, M.M., Eisenhauer, E.L., Long, H.J., Liao, S.Y. \& Tewari, K.S. (2018) Impact of tumour histology on survival in advanced cervical carcinoma: an NRG Oncology/Gynaecologic Oncology Group Study. Br. J. Cancer, 118, 162-170.

Sedlis, A., Bundy, B.N., Rotman, M.Z., Lentz, S.S., Muderspach, L.I. \& Zaino, R.J. (1999) A randomized trial of pelvic radiation therapy versus no further therapy in selected patients with stage IB carcinoma of the cervix after radical hysterectomy and pelvic lymphadenectomy: a Gynecologic Oncology Group Study. Gynecol. Oncol., 73, 177-183.

Shimada, M., Kigawa, J., Nishimura, R., Yamaguchi, S., Kuzuya, K., Nakanishi, T., Suzuki, M., Kita, T., Iwasaka, T. \& Terakawa, N. (2006) Ovarian metastasis in carcinoma of the uterine cervix. Gynecol. Oncol., 101, 234-237.

Shimada, M., Nishimura, R., Hatae, M., Hiura, M., Takehara, K., Tase, T., Yamada, H., Kurachis, H., Sugiyama, T. \& Kigawa, J. (2013a) Comparison of adjuvant chemotherapy and radiotherapy in patients with cervical adenocarcinoma of the uterus after radical hysterectomy: SGSG/TGCU Intergroup surveillance. Eur. J. Gynaecol. Oncol., 34, 425-428.

Shimada, M., Nishimura, R., Nogawa, T., Hatae, M., Takehara, K., Yamada, H., Kurachi, H., Yokoyama, Y., Sugiyama, T. \& Kigawa, J. (2013b) Comparison of the outcome between cervical adenocarcinoma and squamous cell carcinoma patients with adjuvant radiotherapy following radical surgery: SGSG/TGCU Intergroup Surveillance. Mol. Clin. Oncol., 1, 780-784.

Shimada, M., Nagao, S., Fujiwara, K., Takeshima, N., Takizawa, K., Shoji, T., Sugiyama, T., Yamaguchi, S., Nishimura, R. \& Kigawa, J. (2016) Neoadjuvant chemotherapy with docetaxel and carboplatin followed by radical hysterectomy for stage IB2, IIA2, and IIB patients with non-squamous cell carcinoma of the uterine cervix. Int. J. Clin. Oncol., 21, 1128-1135.

Smith, H.O., Tiffany, M.F., Qualls, C.R. \& Key, C.R. (2000) The rising incidence of adenocarcinoma relative to squamous cell carcinoma of the uterine cervix in the United States: a 24-year population-based study. Gynecol. Oncol., 78, 97-105.

Stolnicu, S., Barsan, I., Hoang, L., Patel, P., Terinte, C., Pesci, A., Aviel-Ronen, S., Kiyokawa, T., Alvarado-Cabrero, I., Pike, M.C., Oliva, E., Park, K.J. \& Soslow, R.A. (2018) International Endocervical Adenocarcinoma Criteria and Classification (IECC): a new pathogenetic classification for invasive adenocarcinomas of the endocervix. Am. J. Surg. Pathol., 42, 214-226.

Stolnicu, S., Hoang, L. \& Soslow, R.A. (2019) Recent advances in invasive adenocarcinoma of the cervix. Virchows Arch., 475, 537-549.

Takagi, Y., Matsuoka, Y., Shiomi, T., Nosaka, K., Takeda, C., Haruki, T., Araki, K., Taniguchi, Y., Nakamura, H. \& Umekita, Y. (2015) Cytoplasmic maspin expression is a predictor of poor prognosis in patients with lung adenocarcinoma measuring $<3 \mathrm{~cm}$. Histopathology, 66, 732-739.

Takekuma, M., Shimokawa, M., Nishio, S., Omi, H., Tabata, T., Takei, Y., Nasu, K., Takahashi, Y., Toyota, S., Ichikawa, Y., Arakawa, A., Ito, F., Tsubamoto, H., Mori, T., Hirashima, Y., et al. (2018) Phase II study of adjuvant chemotherapy with paclitaxel and nedaplatin for uterine cervical cancer with lymph node metastasis. Cancer Sci., 109, 1602-1608.

Takeshima, N., Umayahara, K., Fujiwara, K., Hirai, Y., Takizawa, K. \& Hasumi, K. (2006) Treatment results of adjuvant chemotherapy after radical hysterectomy for intermediate- and highrisk stage IB-IIA cervical cancer. Gynecol. Oncol., 103, 618-622.

Tanioka, M., Yamaguchi, S., Shimada, M., Nagao, S., Takehara, K., Nishimura, M., Morita, S., Negoro, S., Fujiwara, K. \& Kigawa, J. (2017) Cisplatin with dose-dense paclitaxel before and after radical hysterectomy for locally advanced cervical cancer: a prospective multicenter phase II trial with a dosefinding study. Med. Oncol., 34, 134.

Tornesello, M.L., Annunziata, C., Buonaguro, L., Losito, S., Greggi, S. \& Buonaguro, F.M. (2014) TP53 and PIK3CA gene mutations in adenocarcinoma, squamous cell carcinoma and high-grade intraepithelial neoplasia of the cervix. $J$. Transl. Med., 12, 255.

Tornesello, M.L., Buonaguro, L. \& Buonaguro, F.M. (2013) Mutations of the TP53 gene in adenocarcinoma and squamous cell carcinoma of the cervix: a systematic review. Gynecol. Oncol., 128, 442-448.

Tsuchida, K., Murakami, N., Kato, T., Okuma, K., Okamoto, H., Kashihara, T., Takahashi, K., Inaba, K., Igaki, H., Nakayama, Y., Nakano, T. \& Itami, J. (2019) Postoperative pelvic intensity-modulated radiation therapy reduced the incidence of late gastrointestinal complications for uterine cervical cancer patients. J. Radiat. Res., 60, 650-657.

Tsuda, H., Jiko, K., Tsugane, S., Yajima, M., Yamada, T., Tanemura, K., Tsunematsu, R., Ohmi, K., Sonoda, T. \& Hirohashi, S. (1995) Prognostic value of $\mathrm{p} 53$ protein accumulation in cancer cell nuclei in adenocarcinoma of the uterine cervix. Jpn. J. Cancer Res., 86, 1049-1053.

Ueda, A., Takasawa, A., Akimoto, T., Takasawa, K., Aoyama, T., Ino, Y., Nojima, M., Ono, Y., Murata, M., Osanai, M., Hasegawa, T., Saito, T. \& Sawada, N. (2017) Prognostic 
significance of the co-expression of EGFR and HER2 in adenocarcinoma of the uterine cervix. PLoS One, 12, $\mathrm{e} 0184123$.

Umayahara, K., Takekuma, M., Hirashima, Y., Noda, S.E., Ohno, T., Miyagi, E., Hirahara, F., Hirata, E., Kondo, E., Tabata, T., Nagai, Y., Aoki, Y., Wakatsuki, M., Takeuchi, M., Toita, T., et al. (2016) Phase II study of concurrent chemoradiotherapy with weekly cisplatin and paclitaxel in patients with locally advanced uterine cervical cancer: the JACCRO GY-01 trial. Gynecol. Oncol., 140, 253-258.

Umekita, Y., Ohi, Y., Sagara, Y. \& Yoshida, H. (2002) Expression of maspin predicts poor prognosis in breast-cancer patients. Int. J. Cancer, 100, 452-455.

Wang, X., Shen, Y., Zhao, Y., Li, Z., Gou, H., Cao, D., Yang, Y., Qiu, M., Li, Q., Liu, J., Yi, C., Liao, Z., Luo, D., Xu, F. \& Bi, F. (2015) Adjuvant intensity-modulated radiotherapy (IMRT) with concurrent paclitaxel and cisplatin in cervical cancer patients with high risk factors: a phase II trial. Eur. J. Surg. Oncol., 41, 1082-1088.

Whitney, C.W., Sause, W., Bundy, B.N., Malfetano, J.H., Hannigan, E.V., Fowler, W.C. Jr., Clarke-Pearson, D.L. \& Liao, S.Y. (1999) Randomized comparison of fluorouracil plus cisplatin versus hydroxyurea as an adjunct to radiation therapy in stage IIB-IVA carcinoma of the cervix with negative para-aortic lymph nodes: a Gynecologic Oncology Group and Southwest Oncology Group study. J. Clin. Oncol., 17, 1339-1348.

Wibur, D.C., Mikami, Y., Colgan, T.J., Park, K.J., Ferenczy, A.S., Rnnett, B.M., Hirschowitz, L., Schneider, A., Loening, T., Soslow, R., McCluggage, W.G., Wells, M. \& Wright, T. (2014) Glandular tumors and precursors. In WHO Classification of Tumors of Female Reproductive Organs, 4th ed., edited by
Kurman, R.J., Carcangiu, M.L., Herrington, C.S. \& Young, R.H. International Agency for Research on Cancer, Lyon, pp.183-194.

Wright, A.A., Howitt, B.E., Myers, A.P., Dahlberg, S.E., Palescandolo, E., Van Hummelen, P., MacConaill, L.E., Shoni, M., Wagle, N., Jones, R.T., Quick, C.M., Laury, A., Katz, I.T., Hahn, W.C., Matulonis, U.A., et al. (2013) Oncogenic mutations in cervical cancer: genomic differences between adenocarcinomas and squamous cell carcinomas of the cervix. Cancer, 119, 3776-3783.

Yaegashi, N. (2020) Gynecologic cancer committee report in 2018. Acta Obstet. Gynaecol. Jpn., 72, 800-856.

Yamaguchi, S., Nishimura, R., Yaegashi, N., Kiguchi, K., Sugiyama, T., Kita, T., Kubushiro, K., Kokawa, K., Hiura, M., Mizutani, K., Yamamoto, K. \& Takizawa, K. (2012) Phase II study of neoadjuvant chemotherapy with irinotecan hydrochloride and nedaplatin followed by radical hysterectomy for bulky stage Ib2 to IIb, cervical squamous cell carcinoma: Japanese Gynecologic Oncology Group study (JGOG 1065). Oncol. Rep., 28, 487-493.

Yessaian, A., Magistris, A., Burger, R.A. \& Monk, B.J. (2004) Radical hysterectomy followed by tailored postoperative therapy in the treatment of stage IB2 cervical cancer: feasibility and indications for adjuvant therapy. Gynecol. Oncol., 94, 61-66.

Yokoi, E., Mabuchi, S., Takahashi, R., Matsumoto, Y., Kuroda, H., Kozasa, K. \& Kimura, T. (2017) Impact of histological subtype on survival in patients with locally advanced cervical cancer that were treated with definitive radiotherapy: adenocarcinoma/adenosquamous carcinoma versus squamous cell carcinoma. J. Gynecol. Oncol., 28, e19. 